13 - ORIGINAL ARTICLE

TECHNICAL SKILL

\title{
Anatomical study of the pigs temporal bone by microdissection ${ }^{1}$
}

\author{
Leandro de Borborema Garcia', José Santos Cruz de Andrade" ${ }^{\mathrm{II}}$, José Ricardo Gurgel Testa ${ }^{\mathrm{III}}$
}

DOI: http://dx.doi.org/10.1590/S0102-86502014001300013

IFellow Master Degree -Medicine (Otolaryngology) Post-Graduate Program - Department of Otorhinolaryngology and Head and Neck Surgery Federal University of São Paulo - Paulista School of Medicine. Substantive scientific and intellectual contributions to the study, conception and design, manuscript preparation, acquisition of data, analysis and interpretation of data, manuscript writing.

IFellow PhD degree - Medicine (Otolaryngology) Post-Graduate Program - Department of Otorhinolaryngology and Head and Neck Surgery - Federal University of São Paulo - Paulista School of Medicine. Manuscript preparation, acquisition of data, manuscript writing.

IIIPhD in Science - UNIFESP; Adjunct Professor at the Department of Otorhinolaryngology and Head and Neck Surgery - UNIFESP-EPM. Medical School of the Federal University of São Paulo - UNIFESP/EPM. Responsible for conception and design, manuscript preparation, critical revision, final approval.

\section{ABSTRACT}

PURPOSE: Initial study of the pig`s temporal bone anatomy in order to enable a new experimental model in ear surgery.

METHODS: Dissection of five temporal bones of Sus scrofa pigs obtained from UNIFESP - Surgical Skills Laboratory, removed with hole saw to avoid any injury and stored in formaldehyde $10 \%$ for better conservation. The microdissection in all five temporal bone had the following steps: inspection of the outer part, external canal and tympanic membrane microscopy, mastoidectomy, removal of external ear canal and tympanic membrane, inspection of ossicular chain and middle ear.

RESULTS: Anatomically it is located at the same position than in humans. Some landmarks usually found in humans are missing. The tympanic membrane of the pig showed to be very similar to the human, separating the external and the middle ear. The middle ear's appearance is very similar than in humans. The ossicular chain is almost exactly the same, as well as the facial nerve, showing the same relationship with the lateral semicircular canal.

CONCLUSION: The temporal bone of the pigs can be used as an alternative for training in ear surgery, especially due the facility to find it and its similarity with temporal bone of the humans.

Key words: Models, Animal. Temporal Bone. Sus Scrofa. Ear Surgery. 


\section{Introduction}

Cadaver Temporal bone dissection is the base for training ear surgery. However, these trainings surgeries are increasingly rare. Nowadays, there is a shortage of temporal bones around the world ${ }^{1}$. Beyond that, the current Brazilian legislation establishes that only those cadavers which remain unclaimed for 30 days can be used for research and educational purposes $^{2}$.

Therefore, animal models are being investigated for otological surgery ${ }^{1}$, because there is a constant need for increasing the surgical skills, as well as creation and development of new surgical techniques ${ }^{3,4}$. Clearly, the greater the morphological similarities between the structures of the model and those of humans, the more valuable the model ${ }^{2,3}$.

The common pig offers a number of advantages for these studies. Many elements of the anatomy and physiology are similar to the human ${ }^{5}$. Besides, the animal belongs to the human daily food chain, easily found in markets and butcherys ${ }^{6}$.

Nevertheless, there is still a shortage of information about the temporal bone of the pig and its use as an experimental model for otological surgery training.

Because of this, the aim of this study is to perform an initial study of the pig`s temporal bone anatomy in order to enable a new experimental model in ear surgery.

\section{Methods}

The study was accomplished in Temporal Bone Microdissection Laboratory - Federal University of São Paulo (UNIFESP with supervision and monitoring of a veterinary, following the Council for International Organization of Medical Sciences (CIOMS) ethical code for animal experimentation and obeyed the norms of the Federal Law number 6,638/1979.

Five temporal bones of Sus scrofa pigs were obtained from UNIFESP - Surgical Skills Laboratory. To extract the temporal bone without injury, a hole saw - 92mm (3.5/8") was necessary. After that, the bones were stored in formaldehyde $10 \%$ for better conservation.

The microdissection and pictures were performed at Temporal Bone Microdissection Laboratory/UNIFESP , using a D.F. Vasconcelos ${ }^{\circledR}$ MC M1233 microscope, Sony ${ }^{\circledR}$ Cybershot DSC-W120 digital camera and Emtec ${ }^{\circledR}$ dissection motor. Water for irrigation and a Nevoni ${ }^{\circledR}$ surgical aspirator (1.3 liters of capacity) were also used to improve and facilitate the microdissection.
The microdissection in all five temporal bone had the following steps: inspection of the outer part, external ear canal and tympanic membrane microscopy, mastoidectomy, removal of external ear canal and tympanic membrane, inspection of ossicular chain and middle ear.

\section{Results}

\section{Outer part of temporal bone}

Anatomically it is located at the same position than in humas. Some landmarks usually found in humans are missing.

The atlanto-occipital joint is vectored backwards and overlaps the mastoid partially (Figure 1).

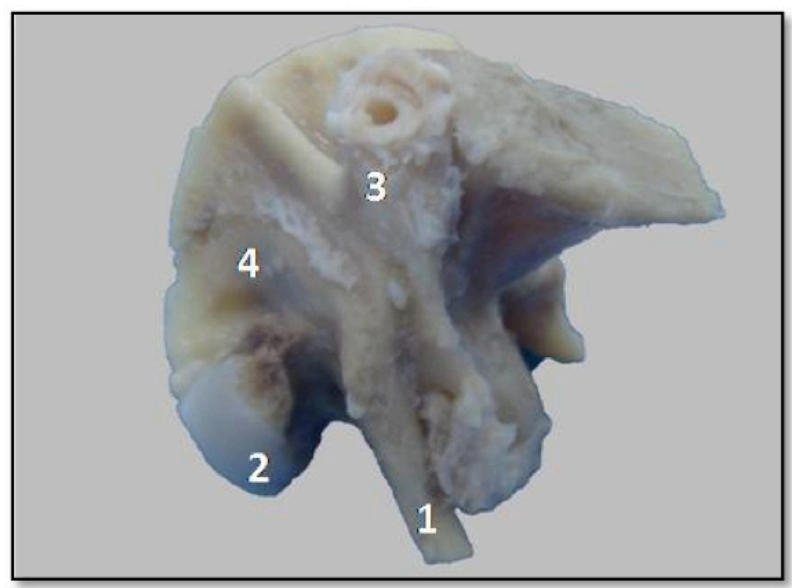

FIGURE 1 - Outer part of the temporal bone: 1. Styloid process; 2. Atlanto-occipital joint; 3. External ear canal; 4. Mastoid area.

\section{External ear canal and tympanic membrane}

The external ear canal also has cartilaginous and bone parts. The tympanic membrane of the pig showed to be very similar to the human, separating the external and the middle ear.

\section{Middle ear}

The appearance is very similar than in humans. The ossicular chain is almost exactly the same (Figure 2), as well as the facial nerve, showing the same relationship with the lateral semicircular canal. 


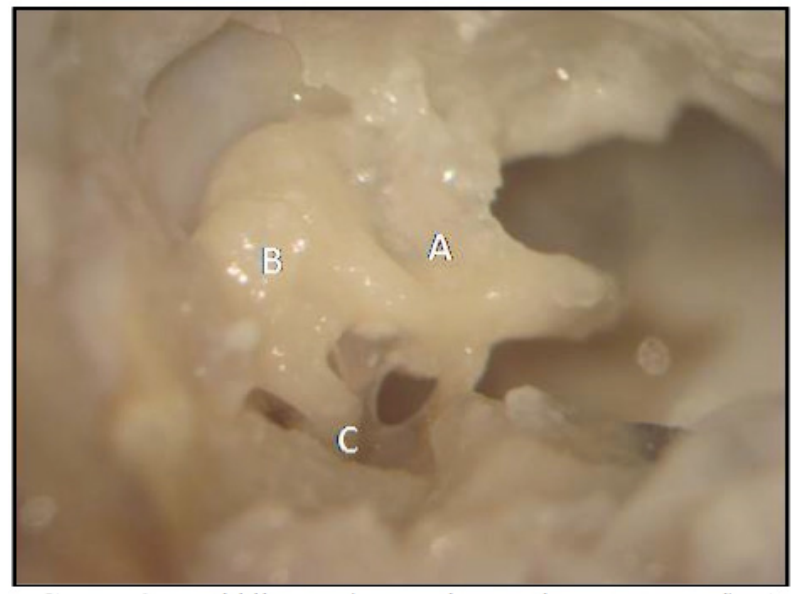

FIGURE 2 - Middle ear (tympanic membrane removed): A. Malleus; B. Incus; C. Stapes.

The floor of the cavity is similar to a honeycomb with a group of aired cells inside the tympanic bulla.

\section{Mastoidectomy}

The classical landmarks as the temporal line, the spina suprameatum and the external ear canal as well as the mastoidal cells cannot be found in the pig.

It is a non pneumatizes mastoid. The pneumatized cells system in the pig is found inferiorly to the tympanic cavity and not posteriorly as in the humans. There is no antrum and in order to visualize the lateral canal it is necessary remove part of the external ear canal (Figure 3).

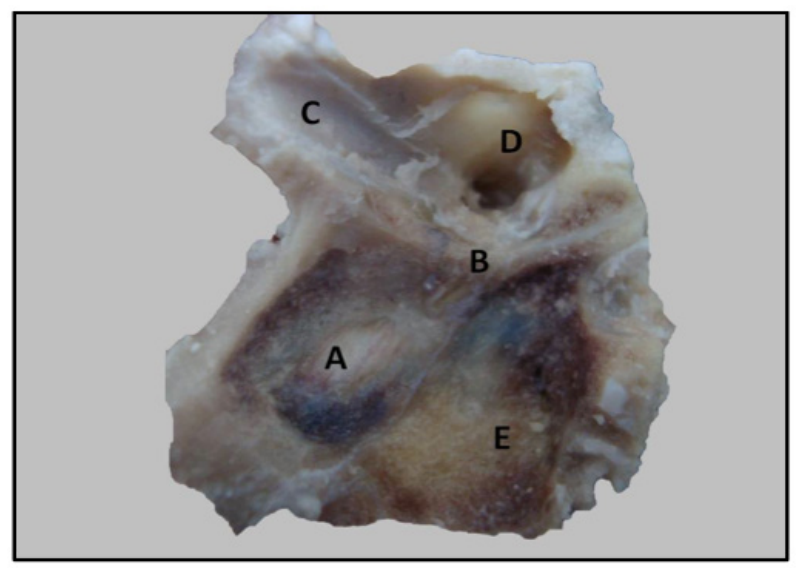

FIGURE 3 - Mastoidectomy: A. Sigmoid sinus; B. Posterior wall of external ear canal; C. External ear canal (partially removed); D. Tympanic membrane; E. Mastoid cavity.

\section{Discussion}

There are several limitations to hearing assessment in animal models, but safety evaluation of an intervention is where models offer much utility. Even before interventions are assessed, animal models can aid in understanding disease etiology and natural history. With careful experimental design, variable extremes not possible in humans can also be studied ${ }^{7}$.

Analyzing the temporal bone of the pig, the first impression is that the bone is very different from the human, because the outer appearance makes a completely different mark. The most disadvantages to use pig as an animal model are the difficult middle ear approach due to very different temporal bone with significant soft tissue coverage and mastoid adipose.

However, when the tympanic membrane and middle ear are analyzed, much similarity can be found. The middle ear is very similar, both in terms of structure dimensions and position to humans.

The ossicular chain, with dimensions and shapes very similar to the humans, become a good option for ossicular training course. According to Bergin et al. ${ }^{7}$, middle ear surgical animal models enable operators to gain experience, confidence and competence with procedures, thereby reducing complications from the learning curve on human patients. In stapes surgery, live animal models expose operators to complications found in human surgery. For example, a floating or depressed footplate, incus dislocation, overhanging or dehiscent facial nerve, excessive bleeding, or perilymph drainage with a dry vestibule are all possible findings.

Another advantage in stapes surgery is the easy manipulation and vision of incudostapedial joint. Comparing with guinea pigs, another very used animal model in research, this last one has the stapes hidden by an overhanding facial nerve and a shelf of bone medial to the nerve, obscuring the incudostapedial joint ${ }^{8}$.

Finally, when considering the facility in acquiring pig`s temporal bone, this gains more importance. Nowadays, the difficult to obtain human temporal bone is a fact ${ }^{9}$.

\section{Conclusion}

The temporal bone of the pigs can be used as an alternative for training in ear surgery, especially due the facility to find it and its similarity with temporal bone of the humans. 


\section{References}

1. Zhao YC, Kennedy G, Hall R, O'Leary S. Differentiating levels of surgical experience on a virtual reality temporal bone simulator. Otolaryngol Head Neck Surg. 2010 Nov;143(5 Suppl 3):S30-5.

2. Okada DM, Sousa AMA de, Huertas R de A, Suzuki FA. Surgical simulator for temporal bone dissection training. Braz J Otorhinolaryngol. 2010;76(5):575-8.

3. Seibel VAA, Lavinsky L, De Oliveira JAP. Morphometric study of the external and middle ear anatomy in sheep: a possible model for ear experiments. Clin Anat. 2006 Sept;19(6):503-9.

4. Seibel VA, Lavinsky L, Irion K. CT-Scan sheep and human inner ear morphometric comparison. Braz J Otorhinolaryngol. 2006;72(3):370-6.

5. Pracy JP, White a, Mustafa Y, Smith D, Perry ME. The comparative anatomy of the pig middle ear cavity: a model for middle ear inflammation in the human? J Anat. 1998 Apr;192(3):359-68.

6. Gurr A, Kevenhörster K, Stark T, Pearson M, Dazert S. The common pig: a possible model for teaching ear surgery. Eur Arch Otorhinolaryngol. $2010 \mathrm{Feb}$;267(2):213-7.

7. Bergin M, Vlajkovic S, Bird P, Thorne P. Systematic review of animal models of middle ear surgery. World J Otorhinolaryngol. 2013;3(3):71-88.
8. Goksu N, Haziroglu R, Kemaloglu Y, Karademir N, Bayramoglu I, Akyildiz N. Anatomy of the guinea pig temporal bone. Ann Otol Rhinol Laryngol. 1992 Aug;101(8):699-704.

9. Gurr A, Pearson MD, S D. Lambs' temporal bone anatomy under didactic aspects. Braz J Otorhinolaryngol. 2011;77(1):51-7.

\section{Correspondence:}

Leandro de Borborema Garcia

Rua Afonso Celso, 1102/74B

04119-061 São Paulo - SP Brasil

Tel.: (55 11)98637-0449

leandroborborema@yahoo.com.br

${ }^{1}$ Research performed at Temporal Bone Microdissection Laboratory, Otology and Neurotology Discipline, Otolaryngology and Head and Neck Department, Federal University of Sao Paulo (UNIFESP), Brazil. 